Case Report

\title{
Subtle de Winter in a 40 Years Old Male with No Chest Pain
}

\author{
Khalid Abdulrahman Ali Ateyyah \\ College of Medicine, Taibah University, Madinah, Saudi Arabia
}

Email address:

kateyyah@taibahu.edu.sa

\section{To cite this article:}

Khalid Abdulrahman Ali Ateyyah. Subtle de Winter in a 40 Years Old Male with No Chest Pain. International Journal of Biomedical Materials Research. Vol. 6, No. 2, 2018, pp. 35-39. doi: 10.11648/j.ijbmr.20180602.12

Received: June 21, 2018; Accepted: July 17, 2018; Published: August 15, 2018

\begin{abstract}
BACKGROUND: It is well known that the Electrocardiogram (ECG) is the first and most important test to diagnose patients with acute coronary syndrome (ACS). ST elevations on ECG in a patient presenting with chest pain is defined as ST elevation myocardial infarction (STEMI) and is confirmed by cardiac catheterization. Various STEMI equivalents have been reported in the literature. Most STEMI equivalents are often missed or not recognized by physicians. So, giving attention to these presentations are very important for physicians and cardiologist. The de Winter ECG pattern is one of the rare STEMI equivalents presentations which deserves emergent reperfusion therapy. CASE REPORT: This case report describes a very subtle ECG pattern which found to have critical occlusion of the proximal left anterior descending (LAD) artery in a previously healthy 40-year-old patient who presented to the Emergency Department (ED) with no chest pain. The patient did not have any risk factors for ACS and was not taking any medication. The initial ECG showed mild ST depression, which was changed to biphasic $\mathrm{T}$ wave later on. Recognizing this specific ECG pattern is important to direct patients toward appropriate management early and prevent delay in diagnoses.
\end{abstract}

Keywords: Acute Myocardial Infarction (AMI), Anterior Wall Acute Myocardial Infarction,

Left Anterior Descending Artery (LAD) Occlusion, de Winter Sign, STEMI-Equivalent,

Acute Coronary Syndrome (ACS), Primary Percutaneous Coronary Intervention (PCI), Revascularization

\section{Background}

Electrocardiogram (ECG) is usually the first and most important test in patients with acute coronary syndrome. It helps in diagnosis and in classifying patients into ST elevation or non-ST elevation myocardial infarction (STEMI). The morbidity and mortality associated with ST-elevation myocardial infarction (STEMI) have been dramatically reduced after the introduction of reperfusion therapy with either fibrinolysis or percutaneous coronary intervention (PCI). However, patients occasionally present without obvious ST elevation on ECG, resulting in delayed diagnosis and reperfusion therapy.

Almost 10 years ago de Winter et al. reported an ECG pattern that is found in about 2\% (30 of 1532) of patients with proximal left anterior descending artery occlusion (acute anterior myocardial infarction) and is often unrecognized by physician.[1] De Winter syndrome is characterized by ST depression and peaked $\mathrm{T}$ waves in precordial leads. Some authors consider this pattern to be an equivalent of anterior STEMI. [1] This is a case of acute left anterior descending (LAD) artery occlusion presenting without obvious ST elevation in ECG but with features mimicking non-ST elevation acute coronary syndrome.

\section{Case Report}

This is a case of a de Winter ECG pattern in a healthy 49-year-old man with no prior medications and no risk factors for acute coronary syndrome. He presented to the ED with left shoulder pain for 4 days, pain localized to left shoulder only, no aggravating or relieving factors, no radiation, no SOB, no chest pain, no nausea or vomiting and No dyspnea. There was no family history of cardiac disease. The first electrocardiograms (ECG), performed at presentation revealed up-sloping ST-segment depressions $<1 \mathrm{~mm}$ in leads $\mathrm{V}_{4-6}$ at the $\mathrm{J}$ point (Figure 1). 


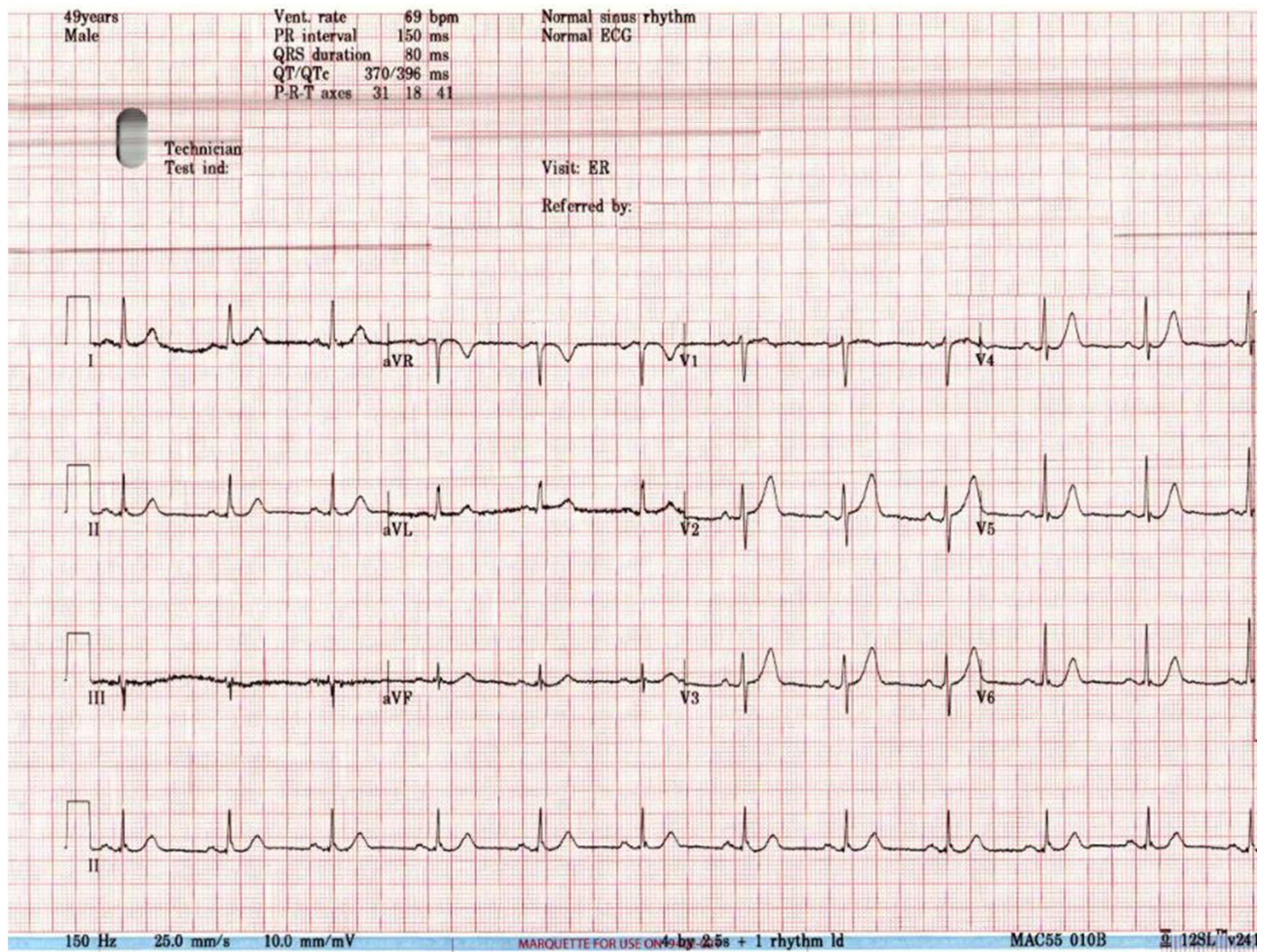

Figure 1. The 12-lead electrocardiogram (ECG) taking at the time of first presentation to the emergency department showing Subtle ST-segment depression in leads $V 4-V 6$.

These changes were suspicious compared to the patient's baseline ECG (Figure 2).

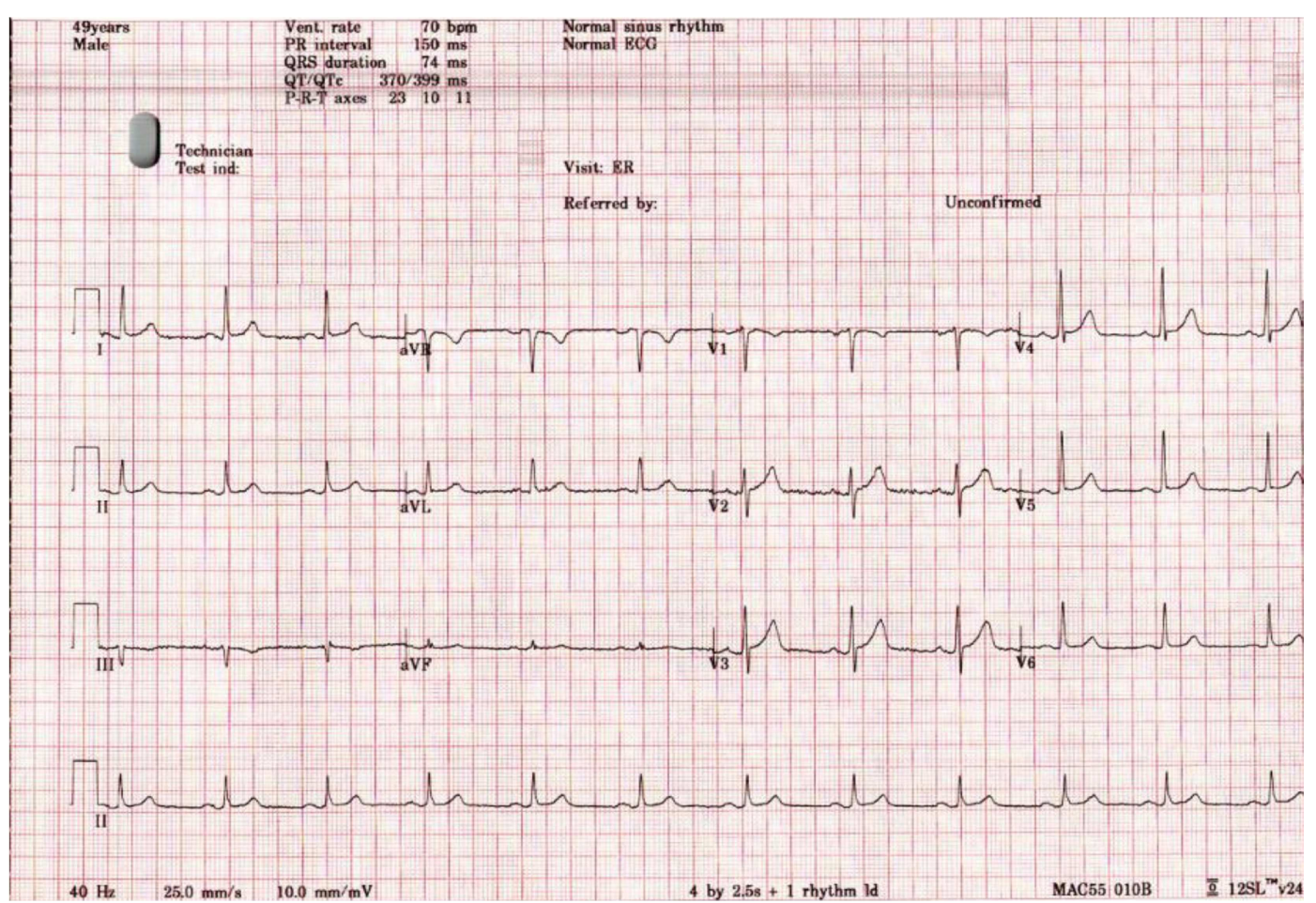

Figure 2. Baseline Normal ECG.

A later ECG revealed a biphasic T wave V2-V5 (Wellen's pattern, Figure 3), and the patient did not complain of any symptoms. 


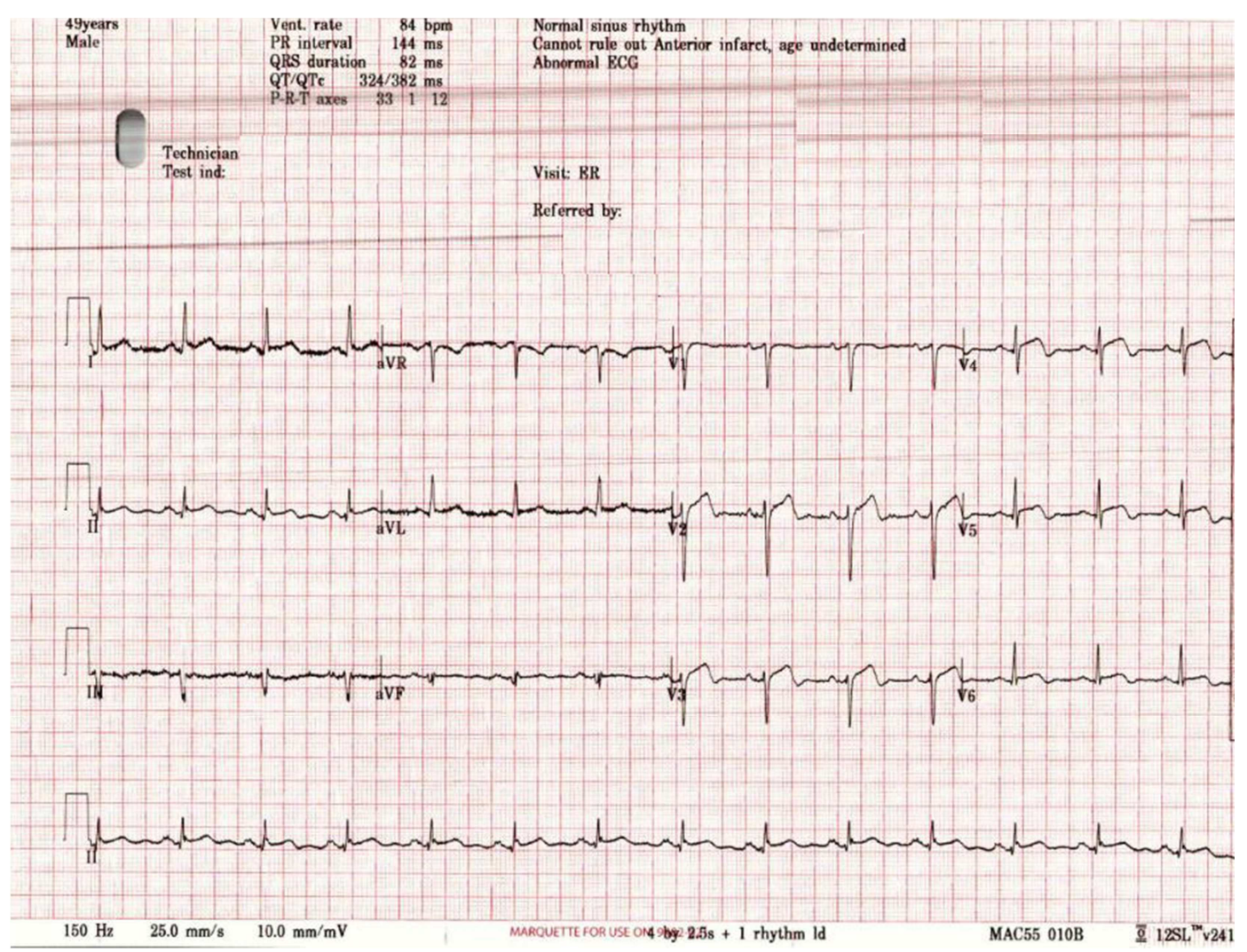

Figure 3. The 12-lead ECG taken at a later time in the emergency department revealing Wellens'sign, Biphasic T wave pattern in leads V3 - V6.

Troponin I level was $15.551 \mu \mathrm{g} / \mathrm{L}$ (normal values $<0.1$ $\mu \mathrm{g} / \mathrm{L})$. The patient was transferred to the cardiac center for urgent cardiac catheterization, which found LAD occlusion (Figures $4,5 \& 6$ ).

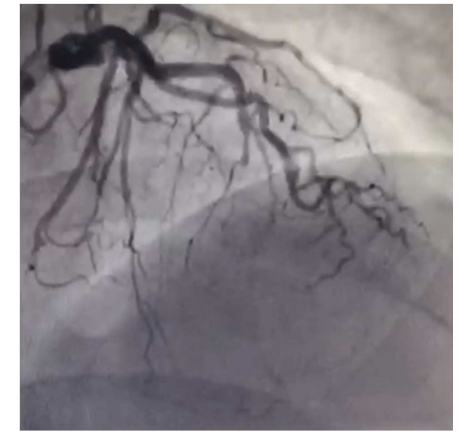

Figure 4. A coronary angiogram revealing left anterior descending (LAD) coronary artery occlusion.

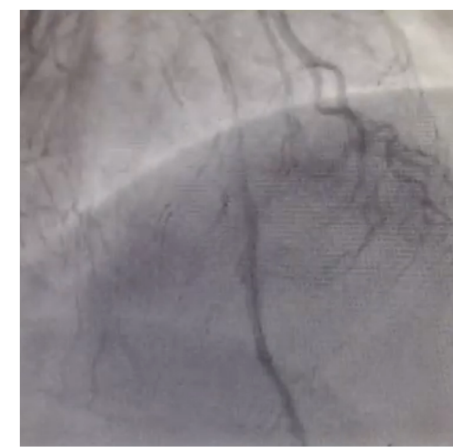

Figure 5. Percutaneous coronary intervention of the LAD coronary artery.

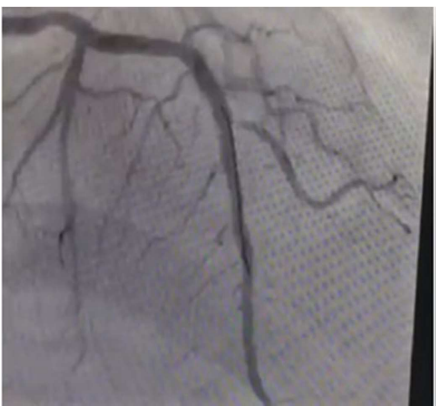

Figure 6. Blood flow was restored after percutaneous coronary intervention of the LAD coronary artery.

\section{Discussion}

In the proper clinical context, ST-segment elevation (measured at the J-point) is considered to be suggestive of ongoing coronary artery acute occlusion in the following cases: at least two contiguous leads with ST-segment elevation $\geq$ $2.5 \mathrm{~mm}$ in men $<40$ years, $\geq 2 \mathrm{~mm}$ in men $\geq 40$ years, or $\geq 1.5 \mathrm{~mm}$ in women in leads $\mathrm{V}_{2}-\mathrm{V}_{3}$ and/or $\geq 1 \mathrm{~mm}$ in the other leads [in the absence of left ventricular (LV) hypertrophy or left bundle branch block LBBB)].[2] In a 2012 subanalysis of the HORIZONS-AMI database, a "semi-STEMI" was defined as maximal STE of $0.7 \mathrm{~mm}-0.9$ $\mathrm{mm}$. [3] Another study found an $18 \%$ prevalence of "subtle" STE $(0.1 \mathrm{~mm}-1.0 \mathrm{~mm})$, with an $86 \%$ rate of acute coronary artery occlusion.[4]

A de Winter sign is generally associated with occlusions in the proximal segment of the LAD and is not mentioned among 
the ECG patterns representing acute left main coronary artery (LMCA) occlusion. [1], [5] It is a distinct form of anterior ST-segment elevation myocardial infarction (STEMI)-equivalent and is characterized by a unique ECG pattern. [1, 6] In 2010, Rokos et al. recognized de Winter pattern as a STEMI equivalent. [7]

The key diagnostic features of the ECG pattern include an upsloping ST-segment depression $>1 \mathrm{~mm}$ at the $\mathrm{J}$ point in the precordial leads; tall, prominent, and symmetrically peaked $\mathrm{T}$ waves with no classic ST-segment elevation in the precordial leads; and slight ST-segment elevation $(0.5-1 \mathrm{~mm})$ in the aVR lead. [8-10]

Various factors, such as individual differences in coronary anatomy, recruitment of collateral channels and repeated episodes of ischemia with preconditioning, the size of the jeopardized myocardium, timing of the ECG recording, partial obstruction causing some residual flow and different phases of the thrombotic cascade, may all be responsible for the various types of ECG changes. The American College of Cardiology (ACC) / American Heart Association (AHA) released non-STEMI guidelines in 2012 and STEMI guidelines in 2013 , and neither mention de Winter ECG signs. [11] Further, the 2017 Guidelines of the European Society of Cardiology (ESC) do not mention the de Winter sign.[12] Whether de Winter T-wave ECG pattern can evolve into STEMI is debatable, and there are arguments that de Winter T-wave pattern is a part of STEMI evolution which was impeded with aggressive antithrombotic/antiplatelet therapy. [13] Zhao et al. suggested that patients showing the de Winter ECG pattern should receive follow-up treatment in accordance with the STEMI guidelines. [14] Thus, it is not a widely recognized type of acute myocardial infarction. Coronary angiography shows that the de Winter ECG sign is a manifestation of complete/partial LAD occlusion. Significance of this pattern lies in that failure to recognize these ECG changes may often lead to undertreatment. [15] Therefore, upon identifying the de Winter ECG, PCI should be performed immediately.

\section{Conclusion}

The characteristic ECG changes of the de Winter ECG pattern may be missed or misdiagnosed as nonspecific. To avoid missing a critical LAD lesion, physicians, paramedics and others involved in the triage of patients should be careful of subtle ECG changes because the classic diagnostic criteria (ST-segment depression $>1 \mathrm{~mm}$ with upsloping ST-segments and tall, symmetrical T-waves in the precordial leads of the 12-lead ECG) are not always present. Such patients need urgent reperfusion therapy.

\section{Consent}

Approved waiver informed consent.

\section{Ethical Approval}

It is not applicable.

\section{Conflict of Interest}

The author declares no conflict of interest.

\section{References}

[1] de Winter RJ, Verouden NJ, Wellens HJ, Wilde AA; Interventional Cardiology Group of the Academic Medical Center (2008). A new ECG sign of proximal LAD occlusion. N Engl J Med. 359(19):2071-2073.

[2] Thygesen K, Alpert JS, Jaffe AS, Simoons ML, Chaitman BR, White HD; Writing Group on the Joint ESC/ACCF/AHA/WHF Task Force for the Universal Definition of Myocardial Infarction, Thygesen K, Alpert JS, White HD, Jaffe AS, Katus HA, Apple FS, Lindahl B, Morrow DA, Chaitman BA, Clemmensen PM, Johanson P, Hod H, Underwood R, Bax JJ, Bonow RO, Pinto F, Gibbons RJ, Fox KA, Atar D, Newby LK, Galvani M, Hamm CW, Uretsky BF, Steg PG, Wijns W, Bassand JP, Menasché P, Ravkilde J, Ohman EM, Antman EM, Wallentin LC, Armstrong PW, Simoons ML, Januzzi JL, Nieminen MS, Gheorghiade M, Filippatos G, Luepker RV, Fortmann SP, Rosamond WD, Levy D, Wood D, Smith SC, Hu D, Lopez-Sendon JL, Robertson RM, Weaver D, Tendera M, Bove AA, Parkhomenko AN, Vasilieva EJ, Mendis S; ESC Committee for Practice Guidelines (CPG) (2012). Third universal definition of myocardial infarction. Eur Heart J. 33(20):2551-2567.

[3] Rokos IC, Farkouh ME, Reiffel J, Dressler O, Mehran R, Stone GW. Correlation between index electrocardiographic patterns and pre-intervention angiographic findings: insights from the HORIZONS-AMI trial (2012). Catheter Cardiovasc Interv. 1;79(7):1092-1098

[4] Martí D, Mestre JL, Salido L, Esteban MJ, Casas E, Pey J, Sanmartín M, Hernández-Antolín R, Zamorano JL. Incidence, angiographic features and outcomes of patients presenting with subtle ST-elevation myocardial infarction (2014). Am Heart J. 168(6):884-890.

[5] Martínez-Losas P, Fernández-Jiménez R. de Winter syndrome (2016). CMAJ. 19;188(7):528.

[6] Gorgels AP. ST-elevation and non-ST-elevation acute coronary syndromes: should the guidelines be changed? (2013) J Electrocardiol. 46(4):318-323.

[7] Rokos IC, French WJ, Mattu A, Nichol G, Farkouh ME, Reiffel $\mathrm{J}$, et al. Appropriate cardiac cath lab activation: Optimizing electrocardiogram interpretation and clinical decision-making for acute ST-elevation myocardial infarction. Am Heart J 2010;160:995-1003.

[8] Verouden NJ, Koch KT, Peters RJ, Henriques JP, Baan J, van der Schaaf RJ, Vis MM, Tijssen JG, Piek JJ, Wellens HJ, Wilde AA, de Winter RJ. Persistent precordial "hyperacute" T-waves signify proximal left anterior descending artery occlusion (2009). Heart. 95(20):1701-1706.

[9] de Winter RW, Adams R, Verouden NJ, de Winter RJ. Precordial junctional ST-segment depression with tall symmetric T-waves signifying proximal LAD occlusion (2016), case reports of STEMI equivalence. $\mathrm{J}$ Electrocardiol. 49(1):76-80.

[10] Samadov F, Akaslan D, Cincin A, Tigen K, Sarı I. Acute proximal left anterior descending artery occlusion with de Winter sign (2014). Am J Emerg Med. 32(1):110.e1-110.e3. 
[11] Birnbaum Y, Nikus K, Kligfield P, Fiol M, Barrabés JA, Sionis A, Pahlm O, Niebla JG, de Luna AB. The role of the ECG in diagnosis, risk estimation, and catheterization laboratory activation in patients with acute coronary syndromes: a consensus document (2014). Ann Noninvasive Electrocardiol. 19(5):412-425.

[12] Ibanez B, James S, Agewall S, Antunes MJ, Bucciarelli-Ducci C, Bueno H, Caforio ALP, Crea F, Goudevenos JA, Halvorsen S, Hindricks G, Kastrati A, Lenzen MJ, Prescott E, Roffi M, Valgimigli M, Varenhorst C, Vranckx P, Widimský P; ESC Scientific Document Group. 2017 ESC Guidelines for the management of acute myocardial infarction in patients presenting with ST-segment elevation: The Task Force for the management of acute myocardial infarction in patients presenting with ST-segment elevation of the European Society of Cardiology (ESC). Eur Heart J. 39 (2,7):119-177. doi: 10.1093/eurheartj/ehx393.

[13] Fiol Sala M, Bayés de Luna A, Carrillo López A, García-Niebla J. The "De Winter Pattern" Can Progress to ST-segment Elevation Acute Coronary Syndrome (2015). Rev Esp Cardiol (Engl Ed). 68(11):1042-3.

[14] Zhao YT, Huang YS, Yi Z. de winters ECG changes and anterior myocardial infarction (2016). QJM. 109(4):269-71.

[15] Goebel M, Bledsoe J, Orford JL, Mattu A, Brady WJ. A new ST-segment elevation myocardial infarction equivalent pattern? Prominent $\mathrm{T}$-wave and J-point depression in the precordial leads associated with ST-segment elevation in lead aVr (2014). Am J Emerg Med. 32(3):287.e5-8. 